\title{
FRONTIER METHODOLOGIES FOR THE DETERMINATION OF EFFICIENCIES IN DISTRIBUTION COSTS ${ }^{1}$ \\ METODOLOGÍAS FRONTERAS PARA LA DETERMINACIÓN DE EFICIENCIA EN COSTOS DE DISTRIBUCIÓN
}

\author{
Raúl Sanhueza Hormazábal ${ }^{2} \quad$ Hugh Rudnick Van de Wyngard ${ }^{3}$ \\ Recibido 28 de diciembre de 2006, aceptado 8 de agosto de 2007 \\ Received: December28, 2006 Accepted: August 8, 2007
}

\begin{abstract}
RESUMEN
Este trabajo analiza la eficiencia de empresas de distribución eléctrica, bajo el punto de vista del criterio de la eficiencia productiva. La metodología de análisis consiste en la estimación de funciones de costo de producción frontera, una paramétrica y otra no paramétrica. A partir de las mismas se obtienen dos medidas de la eficiencia técnica individual de cada explotación, lo que deja en evidencia acciones y estrategias que conducen a una reducción de costos para las empresas de distribución. Se ilustra su aplicación dentro del marco del último proceso regulatorio chileno.
\end{abstract}

Palabras clave: Sistemas de distribución, regulación de sistemas de distribución, fronteras de eficiencias, fronteras estocásticas, análisis envolvente de datos.

\section{ABSTRACT}

The efficiency of electric distribution companies is assessed under a productive efficiency criterion viewpoint. The analysis methodology consists of the estimation of frontier production costs functions; a parametric and a non parametric function. Two individual technical efficiency measurements for the distribution business are obtained from these functions. The assessment confirms actions and strategies that result in cost reductions in distribution companies. An application within the framework of the last Chilean regulatory process is illustrated in this work.

Keywords: Distribution companies, distribution regulation, benchmark regulation, data envelopment analysis, efficiency frontiers, stochastic frontiers.

\section{INTRODUCTION}

The electric distribution sector is a fundamental element in the basic infrastructure of any country. Thus, governments worldwide are looking at regulations that assure an economic development of what is a monopolistic activity, so that demand growth is supplied in an efficient manner. Benchmark regulations are being used, defining growing efficiency requirements to the distribution companies. This has been the case in the Latin-American electric sector, where after an in depth restructuring, distribution companies have had to make important efforts to adapt to a new environment and compete with the benchmarks, facing the challenge of reaching specified levels of efficiency.
Thus, with the current regulatory policies, the maximization of the companies' returns is subject to price policies and quality of service requirements, which respond to the services needed by the customers. However, behind these benchmark regulations there are many matters that are not clearly defined and that are key to the development of the sector. Among these, one stands out and it is the definition of the price for the distribution service. The regulator establishes different methodological options that do not necessarily consider the particular structural and revenue characteristics of the distribution activity. To establish an adequate price system, the regulator must make distribution companies operate with reduced production costs. For that purpose, it must know if the electric distribution companies are, or are not, operating with the maximum technical and scale efficiency.

\footnotetext{
1 This work was supported by Fondecyt 1040339 and Universidad de Tarapacá Project 8721-05 and 8723-06.

2 Escuela Universitaria de Ingeniería Eléctrica-Electrónica. Universidad de Tarapacá. Arica, Chile. E-mail: sanhueza@uta.cl

3 Departamento de Ingeniería Eléctrica. Pontificia Universidad Católica de Chile. Casilla 306, Correo 22. Santiago, Chile. E-mail: h.rudnick@ieee.org
} 
Thus, it becomes of paramount importance to estimate and analyze the technical efficiency of the distribution activity, as represented not only by a single company, but by a group of companies. The results thus obtained would be valid orientation to determine if it is possible to reduce production costs, while providing the same service with identical quality conditions.

A first objective of this work is to review and compare the tools that allow evaluating the level of efficiency of a group of electric distribution companies. A second objective is to analyze the variables that can determine the efficiency levels reached, and attempt to clarify which are the optimal characteristics of an efficient distribution business. A third objective is to contrast the relationship existing between the efficiency and the unit cost.

\section{FRONTIER METHODOLOGIES IN BENCHMARKING}

When the operation of different regulated companies, whether electric distributions ones or not, is compared in a benchmark process, it is common to do it contrasting if they are more or less efficient. This comparison necessarily has to consider the factors that govern the production function of the activity of the companies, determined through efficiency and productivity indexes or measurements.

As a basic concept, productivity is relatively easy to define. It is the coefficient between the amount of product (output) and the amount of supplies (input) for the specific production situation. The productivity results that can be obtained are influenced by the differences in production technology, differences in the efficiency of the productive process, and differences due to exogenous variables that affect production $[1,2]$. The productivity component resulting from the differences in the efficiency of the productive process is frequently called "productive efficiency".

Productive efficiency is defined as the capacity of the company to produce a product at a minimum cost. To reach the minimum cost, the company must use its inputs efficiently (technical efficiency) and must choose the right input combination given their relative price (assignment efficiency). In the former case, the technical efficiency is defined in function of the production possibility and is measured as a coefficient between the observed production and the maximum potential production that can be obtained given a group of inputs, or as the coefficient between the total minimum total potential input required and the effectively total used, given a group of outputs. In the latter case, assignment efficiency, the efficiency optimal can be defined in terms of costs, revenues, profits or any other objective of the company that is subject to quantity and price restrictions; therefore this efficiency component has a character that is purely economic. In this manner, productive efficiency requires both components, the technical and assignment efficiency.

The method to empirically measure productive efficiency is based on the measurement of the distance to the frontier that represents the maximum efficiency [3]. As the best behavior is unknown, the best practice observed among the sample of companies under study is considered as an efficient reference. Thus, efficiency indexes are calculated for each company by comparing it with those that have a better economic behavior. In this manner, a measure of efficiency that has a relative character is obtained, namely, it depends on the sample under study. In addition, the composite efficiency of two components is considered; the technical efficiency and the assignment efficiency. The technical efficiency reflects the ability to obtain the maximum amount of outputs, given the inputs, and the assignment efficiency reflects the ability to use the inputs in the optimal proportions, given their respective prices [3]. Specifically, the productive efficiency requires both components, the technical and efficiency assignment.

To obtain the efficiency measurements for a group of companies, through data analyses oriented to determine a maximum production or minimum cost entails a broad range of methods, among which there are econometric and mathematical programming techniques.

\section{Stochastic Parametric Frontiers}

The Stochastic Parametric Frontiers [4, 5] are econometric methods that arise from the idea that the deviations from the frontier are not necessarily under the full control of the analyzed company. In this approach, the frontier is defined as a function of an efficient production to which two disturbances are added: $v$, a symmetrical disturbance that includes the random noise and $u$, a biased disturbance that is originated by technical inefficiencies. In this manner, external events that affect the production function are normally distributed, $\mathcal{N}\left(0, \sigma_{v}^{2}\right)$, affecting the company by favorable or unfavorable external conditions. However, for $u$, the inefficiency term, various distributions have been proposed; normal mean distribution [4], exponential distribution [5], normal truncated distribution [6] and Gamma distribution [7]. There is no a priori reason to prefer any specific type of distribution on the errors. However, the different simulation exercises made in [7] 
indicate that the simplest model, from the econometric viewpoint, is the normal mean distribution [4].

The problem that arises in these methods is that the $u$ component ca not be observed and must be inferred from the composite error term, $\varepsilon=v+u$. The separation of noise and inefficiency components is made from the conditional expectation of $u$ given $\varepsilon$ [8].

\section{The Data Envelopment Analysis}

The Data Envelopment Analysis (DEA) is an optimization technique built to measure the relative efficiency of a group of organizational units, Decision Making Units (DMUs) where the presence of multiple supplies (inputs) and products (outputs) make it difficult to compare their performance. DEA provides a method to compare efficiency without knowing the production function, namely, without needing to know a functional relationship between inputs and outputs.

Assuming there are $n$ DMUs, each one with $m$ inputs and $s$ outputs, the relative efficiency result of a test $\mathrm{DMU}_{0}$ is obtained solving the following linear programming model [9].

$$
\min \theta_{0}
$$

subject to :

$$
\begin{array}{cc}
\boldsymbol{\theta}_{0} x_{i 0}-\sum_{j=1}^{n} \lambda_{j} x_{i j} \geq 0 ; & i=1, \cdots, m \\
-y_{r 0}+\sum_{j=1}^{n} \lambda_{j} y_{r j} \geq 0 ; & r=1, \cdots, s \\
\lambda_{j} \geq 0 ; & j=1, \cdots, n
\end{array}
$$

In this problem, the $\mathrm{DMU}_{0}$ under evaluation is compared to all the DMUs or the linear combination of inputs or outputs producing the same or more than the $\mathrm{DMU}_{0}$, consuming less or the same as the $\mathrm{DMU}_{0}$, respectively. In this manner, if the test DMU is efficient, the programming model has not found among the DMUs a combination of amounts of inputs and outputs with which the same or more than the $\mathrm{DMU}_{0}$ is produced. Therefore, it assigns the value of one to $\theta_{0}$. On the contrary, if the test DMU is inefficient, the programming model has identified a group of DMUs which inputs and outputs create a fictitious DMU that produces the same or less than the $\mathrm{DMU}_{0}$.

In this procedure the efficiency measurement can result from the comparison of different scale units, a possibility that in practice can be inadequate. To solve this problem, it is possible to propose a model that considers the possibility of having inefficiencies due to the differences in the operational scales of each DMU [10], in which case it is necessary to add to the problem the restriction of having $\lambda_{j}$ equal to one. This restriction ensures that the model evaluates the pure technical efficiency without includin scale considerations.

\section{APPLICATION}

The formulated methodology is applied to assess the Chilean regulatory process, which determined the distribution tariffs for the 2000-2004 period. The data used in the analysis corresponds to the information submitted by the Chilean regulator for the tariff process. The analyzed sample is a cross section, with the year 2000 as reference, and corresponds to 35 companies that cover all the distribution zones in the country.

To estimate the parametric frontier, it has been assumed that it corresponds to a trans-logarithmic function. Once developed and taking into account the variables considered in the application, the function to be estimated is:

$$
\begin{aligned}
& \ln (C D)=\beta_{0}+\beta_{1} \ln (P L)+\beta_{2} \ln (P K)+\beta_{3} \ln (E V E N D)+ \\
& \beta_{4} \ln (E V E N D)^{2}+\beta_{5} \ln (K M T)+\beta_{6} \ln (K M T)^{2}+u+v
\end{aligned}
$$

$$
\begin{gathered}
v \sim N\left(0, \sigma_{v}^{2}\right) \\
u \geq 0, \quad u \sim N\left(m_{u}, \sigma_{u}^{2}\right) \\
m_{u}=\alpha_{0}+\alpha_{1} \ln (R C L T)+\alpha_{2} \ln (R K M L)
\end{gathered}
$$

In this approach, the variables that determine the cost function are the ones that are regularly used in literature $[11,12]$. They are the total distribution costs (CDs), composed by the capital and business costs, the inclusion of price variables such as the work price $(P L)$ that has been defined here through the labor coefficient (REMUN) and the number of workers (NTRAB). The capital price $(P K)$ is represented through a coefficient that relates the VNR (replacement value of installations) and the total lines' length, value that clearly acts as a proxy for the capital price. In addition, there are other input variables such as EVEND, the energy sales as the primary activity executed by each company, KMT, the network size measured through the total line high and low voltage kilometers. This last variable captures the size of the distribution system managed by the companies and ensures that, for example, a large rural distribution company is not penalized in the efficiency evaluation when compared to a distribution company that renders the service in a city. Together with the number of transformers, this variable 
is also used to represent the capital cost [11]. All these variables are fixed in the short term and they efficiently describe the service, the system and up to a certain level, the environment faced by distribution companies. Table 1 shows the distribution companies' descriptive statistics. KWT is the maximum demand (a proxy of the transformation capacity required), CLTST is the total number of clients (a proxy for the number of connection points), and CEXPLT are the operation costs (high and low voltage). Chilean pesos are used.

The sample is formed by different types of companies, with predominance from distribution companies that have a high percentage of non-urban consumption. The data indicates that there are important differences in size and activities executed by the companies. One of the smallest companies does not sell more than two thousand GWh per year, while one of the largest one sells more than six million GWh.

Table 1. Descriptive statistics of variables used.

\begin{tabular}{|l|r|r|r|r|}
\hline & \multicolumn{1}{|c|}{ Media } & Desv. Std. & Minimum & Maximum \\
\hline EVEND (GWH) & 465 & 1.206 & 2 & 6.784 \\
\hline KWT & 124.208 & 319.445 & 1.814 & 1.801 .593 \\
\hline CLTS & 111.671 & 231.268 & 1.352 & 1.225 .486 \\
\hline KMT & 2.264 & 2.975 & 18 & 10.547 \\
\hline CEXPLT & 433.992 & 11.168 .397 & 108.491 & 63.410 .184 \\
\hline VNR & 2.5649 .909 & 52.222 .650 & 394.850 & 287.349 .725 \\
\hline NTRAB & 166 & 372 & 19 & 1.351 \\
\hline REMUN (M\$) & 965,6 & 1.677 .294 & 29 & 8.355 \\
\hline
\end{tabular}

The component that reflects the inefficiency in the frontier is the non-negative random variable $u$ and the disturbance term is $v$ that accounts for the effect of the measurement errors and unobserved random errors in the variables.

In line with the common practice, the random term $v$ is distributed independently among the companies according to a normal with a mean of zero and variance of $\sigma^{2}$, $\mathcal{N}\left(0, \sigma^{2}\right)$. For the inefficiency term, $u$ follows a non-negative normal mean, whose mean depends on the variables that explain $\mathcal{N}+\left(m u, \sigma_{u}^{2}\right)$, where $m u$ is the linear specification of the technical inefficiency, to be able to capture external effects that may influence the companies' efficiencies and that are not directly controllable by them. In this manner, the percentage of high voltage clients with respect to the total amount of clients (RCLT) and the percentage of high voltage lines' length with respect to the total line length (RKML) are considered.

The maximum likelihood estimation, with deviations with respect to the model's mean, was made with a cross-section single stage estimation, using the STATA software [13]. Table 2 shows the representative first-order parameters for the frontier (with constant defined by the logarithmic model).

Table 2 shows the estimation results that include the coefficients obtained when using the least squares estimator. These coefficients are a linear estimation of the cost function and do not allow any efficiency prediction. These coefficients are included here with the sole purpose of comparing them with the stochastic frontier model coefficients. In the stochastic frontier model (2), the estimation considered a normal mean distribution for the inefficiency term.

Table 2. Estimated parametric frontiers.

\begin{tabular}{|l|c|c|c|c|c|c|}
\hline & \multicolumn{2}{|l|}{ Least Squares Estimator } & \multicolumn{2}{l|}{ Stochastic Parametric Frontier } \\
\hline Variable & Coef. $^{(\mathbf{d})}$ & Std Dev & t-Estd. & Coef. $^{(\mathbf{d})}$ & Std Dev & t-Estd. \\
\hline constant & $7,38108^{* *}$ & 0,77099 & 9,57 & $7,08727^{* *}$ & 0,90781 & 7,81 \\
\hline Ln (PL) & $-0,10209^{*}$ & 0,07021 & $-1,45$ & $0,13382^{*}$ & 0,10830 & 1,24 \\
\hline Ln (PK) & $-0,18533^{*}$ & 0,11486 & $-1,61$ & $0,02788^{*}$ & 0,08569 & 0,33 \\
\hline Ln (EVEND) & $-0,20179^{* *}$ & 0,07113 & $-2,84$ & $0,01608^{* *}$ & 0,00502 & 3,20 \\
\hline Ln (EVEND) $)^{2}$ & -- & -- & -- & 0,01624 & 0,01639 & 0,99 \\
\hline Ln (KMT) & $0,29592^{* *}$ & 0,08456 & 3,50 & 0,37971 & 0,07650 & 4,96 \\
\hline constant & -- & -- & -- & 0,05574 & 0,01970 & 2,83 \\
\hline Ln (RCLT) & -- & -- & -- & 0,94706 & 0,21864 & 4,33 \\
\hline Ln (RKML) & -- & -- & -- & 1,21513 & 0,41943 & 2,90 \\
\hline
\end{tabular}

(d) **, *: significance at $0.1 \%$, and $10 \%$. 
In general, the frontier's parameters are highly significant, except for the ones associated to the $\ln (P L)$ and $\ln (P K)$ variables, which are less significant in the study model. It is also observed that the linear estimation of the inefficiency presents a high relevance with respect to the coefficient associated to the line's length in kilometers.

Once the cost frontier is estimated, it is possible to calculate the efficiency for each company. However, as we intend to compare these results with the ones obtained through a non-parametric frontier, we calculated it as $\exp \left(-\mathrm{E}\left(\mathrm{u}_{\mathrm{i}} \mid \mathrm{e}_{\mathrm{i}}\right)\right)$, because the function is expressed in logarithms.

Non-parametric frontier

The efficiency results of each unit are obtained solving the linear programming problem (1), and these results can be corrected using a bootstrap procedure in order to give a statistical character to these results [14]. The differences in size become an important factor that requires establishing a separation between the companies in terms of their tariff treatment. In fact, previous to the execution of the studies, the regulator recognized the existence of economies of scale in this activity in the 2000 process, which led to classify the companies in six service areas [17]. This is the means to handle the different economies of scale in the model firm benchmarking process. Thus, the classification of each company within a service area becomes a crucial factor, as it defines the comparison pattern.

Comparison of results for both frontiers

The efficiency results found out through the DEA methodology, bootstrap correction and stochastic parametric frontier are shown in table 3. This table also shows the frequency distribution and the basic descriptive statistics for these results.

The differences observed are mainly due to the characteristics of the methodology used. DEA assigns any deviation from the frontier as inefficiency, while the stochastic parametric methodology distinguishes if this deviation has been caused by the inefficiency or by an arbitrary disturbance. This fact explains the lower efficiency index assigned by DEA to inefficient companies compared to the stochastic technique, and in the other extreme, a higher efficiency index for efficient companies compared with the stochastic methodology.

The level of efficiency resulting from the stochastic parametric frontier presents a Pearson correlation coefficient with the efficiency obtained with the bootstrap DEA methodology of 0.904 and the significant coefficient was $1 \%$. Therefore, we can conclude that for the group of companies considered, the two types of analyses offer similar results. On the other hand, as the model's parameters are obtained as deviations from the mean, they become representative of the respective cost function elasticities.

Figure 1 shows the behavior of these efficiency results for each of the companies ordered according to the DEA efficiency in an ascending sequence.

Similarly, the analysis of the function estimated for the cost frontier allows studying the properties of the productive process. This is so as this is an efficient costs frontier where the parameters are representative of the respective cost function elasticities for the average company.

Table 3. Reference companies and conformation of areas.

\begin{tabular}{|c|c|c|c|c|c|c|}
\hline & \multicolumn{2}{|c|}{ DEA } & \multicolumn{2}{|c|}{ DEA-Bootstrap } & \multicolumn{2}{|c|}{ Stochastic Frontier } \\
\hline Efficiency & Numb. Obs & $\%$ & Numb. Obs & $\%$ & Numb. Obs & $\%$ \\
\hline $0,00-0,55$ & 6 & 17,0 & 10 & 28,6 & 13 & 37,1 \\
\hline $0,55-0,75$ & 8 & 22,9 & 4 & 11,4 & 1 & 2,9 \\
\hline $0,75-0,80$ & 1 & 2,9 & 4 & 11,4 & 1 & 2,9 \\
\hline $0,80-0,85$ & 3 & 8,6 & 1 & 2,9 & 6 & 17,0 \\
\hline $0,85-0,90$ & 1 & 2,9 & 0 & 0 & 2 & 5,8 \\
\hline $0,90-0,95$ & 3 & 8,6 & 3 & 8,6 & 11 & 31,4 \\
\hline $0,95-1,00$ & 13 & 37,1 & 13 & 37,1 & 1 & 2,9 \\
\hline Media & \multicolumn{2}{|c|}{0,7914} & \multicolumn{2}{|c|}{0,7525} & \multicolumn{2}{|c|}{0,7829} \\
\hline Std, Dev, & \multicolumn{2}{|c|}{0,2197} & \multicolumn{2}{|c|}{0,2471} & \multicolumn{2}{|c|}{0,1543} \\
\hline Minimum & \multicolumn{2}{|c|}{0,3392} & \multicolumn{2}{|c|}{0,3095} & \multicolumn{2}{|c|}{0,4723} \\
\hline Maximum & \multicolumn{2}{|c|}{1,0000} & \multicolumn{2}{|c|}{0,9956} & \multicolumn{2}{|c|}{0,9651} \\
\hline
\end{tabular}




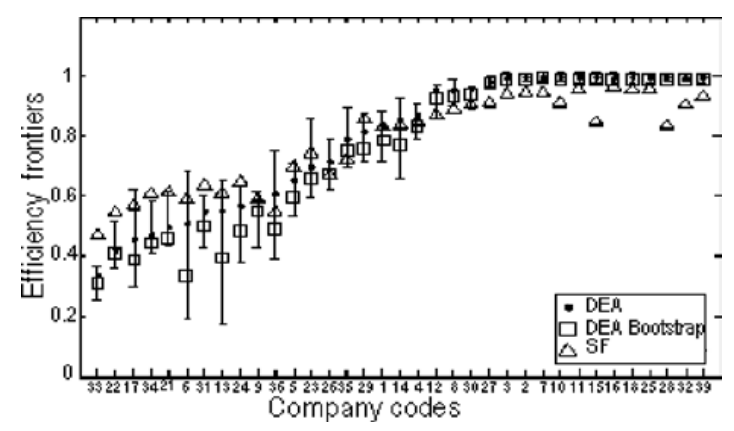

Figure 1. Costs with different frontier models.

\section{Scale Performances}

The scale efficiency for the total cost functions is calculated as the inverse of the sum of all logarithmic partial derivatives of the total cost regarding each relevant output, minus 1 [15].

According to the specified model, the scaled efficiency measures the costs reaction in face of an increase that is proportionally equal in the output, as an increase of the sold energy and an increase in the service area, namely, variation that is equivalent to an expansion of the output variables. However, we must consider that these measurements of scaled partial economies perhaps are not as relevant within the cost functions, because their effect is divided among various outputs. In this manner, the scaled efficiency -that measures the total effect of the expansion of energy sales, keeping KMT and CLTS constant - can be obtained from the elasticities of the average cost function through EEP + 1, namely:

$$
E E=\frac{1}{1+\frac{\partial \ln V A D}{\partial \ln E V E N D} \frac{\ln E V E N D}{\ln V A D}}
$$

where VAD is the distribution unit cost.

For the group of distribution companies analyzed, the results found indicate the presence of increasing scaled performances,

Table 3. Efficiency to scale.

\begin{tabular}{|c|c|}
\hline $\begin{array}{c}\text { Least squares } \\
\text { estimation }\end{array}$ & $\begin{array}{c}\text { Stochastic Parametric } \\
\text { Frontier }\end{array}$ \\
\hline 1,121 & 1,159 \\
\hline
\end{tabular}

The efficiency on scale, evaluated by the model, Table 3 , is similar to the obtained one by square minimums. Therefore, many of the companies of the sample are excessively small and have not reached a minimum scaled efficiency.

\section{CONCLUSIONS}

This work is part of an effort being developed worldwide in the regulation at the distribution level. The aim is to consolidate a theoretical and methodological procedure to evaluate the efficiency of distribution companies. It is a contribution to research on the use of classical organizational theory criteria in the institutional evaluation of distribution companies, establishing new concepts and adapting them to the specifications and characteristics of the activities of these institutions.

The regulatory framework based on efficient companies has been applied for many years in many Latin-American countries and there is an increasing interest worldwide on following this path [16]. However, there is a lack of quantitative evaluation procedures adequate for the specification and characterization of an efficient company and used as a benchmark for distribution companies. The incentive is there to contribute with an approach to solve this problem.

In summary, and considering the requirements, this work applies a methodology that formulates, develops and uses frontier techniques to obtain indicators for the productive efficiency, and to determine the distribution added value of groups of distribution companies that are subject to an efficient-company regulatory scheme. The procedure developed is conceptually clear, technically correct, and operationally applicable; and simultaneously considers the various factors that determine the companies' activities and their interrelationships. In addition, it is consistent with the criteria used in the efficient-company regulatory scheme and it is coherent with modern comparative efficiency analysis techniques.

On the other hand, the frontier methodology can consider the complexity of multiple aspects of the distribution companies' activities, jointly considering the various factors that characterize the diversity of their objectives and investment plans.

\section{REFERENCES}

[1] J.T. Weyman. "Problems of Yardstick Regulation in Electricity Distribution”. Bishop, Kay and Mayer. The Regulatory Challenge. Oxford University Press. 1992.

[2] M. Pollitt. "Ownership and Performance in Electric Utilities". Oxford University Press. Oxford 1995. 
[3] M.J. Farrel. "The Measurement of Productive Efficiency". Journal of the Royal Statistical Society. Series A. Part III. Vol. 120, pp. 253-290. 1957.

[4] D.J. Aigner, C.A.K. Lovell and P.J. Schmidt. "Formulation and Estimation of Stochastic Frontier Production Functions Models". Journal of Econometrics. Vol. 6, pp. 21-37. 1977.

[5] W. Meeusen and J. Van Den Broeck. "Efficiency Estimation from Cobb-Douglas Production Functions with Composed Error". International Economic Review. Vol. 18 N² 2, pp. 435-444. June, 1977.

[6] R. Stevenson. "Likelihood Functions for Generalized Stochastic Frontier Estimation". Journal of Econometrics. Vol. 13, pp. 57-66. 1980.

[7] W. Greene. "A Gamma-distributed Stochastic Frontier Model". Journal of Econometrics. Vol. 46, pp. 141-164. 1990.

[8] J. Jondrow, C.A.K. Lovell, I.S. Materov and P. Schmidt. "On the Estimation of Technical Inefficiency in the Stochastic Frontier Production Function Model". Journal of Econometrics. Vol. 19, pp. 233-238. 1982.

[9] A. Charnes, W. Cooper and E. Rhodes. "Short Communication: Measuring the Efficiency of Decision Making Units". European Journal of Operational Research. Vol. 3 N$^{\circ}$ 4, p. 339. 1979.

[10] R.D. Banker. "Estimating most productive scale size using Data Envelopment Analysis". European
Journal of Operational Research. Vol. 17, pp. 35-44. 1984.

[11] G.C. Scarsi. "Local Electricity Distribution in Italy: Comparative Efficiency Analysis and Methodological Cross-checking". Working Paper 16, Fondazione Erico Mattei. 1999.

[12] M. Filippini, J. Wild and M. Kuenzle. "Scale and Cost Efficiency in the Swiss Electricity Distribution Industry: Evidence from a Frontier Cost Approach". Swiss Federal Institute of Technology. 2001.

[13] Stata Statistical Software. Release 8.0. College Station, TX: Stata Corporation. 2003.

[14] R. Sanhueza, H. Rudnick and H. Lagunas. "DEA Efficiency for the Determination of the Electric Power Distribution Added Value". IEEE Transactions on Power Systems. Vol. $19 \mathrm{~N}^{\circ} 2$, pp. 919-925. 2004.

[15] J.C. Panzar and R. D. Willig. "Economies of Scope". The American Economic Review. Vol. 71 No 2, pp. 268-272. 1981.

[16] Bundesnetzagentur. "Incentive regulation in the German electricity and gas sector-efficiency and reliability to set the yardstick". International scientific conference. Bonn. 25-26 April, 2006.

[17] GTD Consultants. "Study of tariff formulae applied to the distribution of electric power, subject to maximum price fixation". Distribution Value Added 2000 process. Santiago, Chile. March, 2002. 